\title{
Disposable pudendal nerve stimulator: evaluation of the standard instrument and new device
}

\author{
J ROGERS, M M HENRY, AND J J MISIEWICZ \\ From the Department of Gastroenterology and Nutrition, Central Middlesex Hospital, London
}

SUMmary A disposable version of the pudendal nerve stimulator using flexible printed circuit (FPC) technology has been developed and manufactured in our department. Evaluation of this instrument against the standard is reported.

In 1984 Kiff and Swash' were the first to describe pudendal nerve stimulation in investigation of the pathophysiology of idiopathic (neurogenic) faecal incontinence. Their technique was developed from that of electro ejaculation described by Brindley, ${ }^{2}$ for patients with impotence caused by paraplegia. The original device consisted of a rubber finger stall with two stimulating electrodes mounted on the tip and two recording electrodes mounted at the base. Though a fairly reliable instrument, it required disinfection in glutaraldehyde solution between patients and prolonged drying to prevent shorting of the electrodes.

A modified and more reliable version of this reuseable type of pudendal nerve stimulator was developed in our department and is used by a number of anorectal physiology units in this country and overseas. The main drawback with this device is that it needs thorough cleaning between subjects, to prevent cross infection. Using the techniques used in the manufacture of flexible printed circuits we have developed a disposable pudendal nerve stimulator of the design shown in Figure 1. The electrodes are mounted in the same relative positions as in the reuseable model and are of the same dimensions. The flexible printed circuits terminals from the new stimulator are connected to the EMG machine by a reuseable lead by means of a quick release clip, which can be engaged and disengaged easily by a single

Address for correspondence: Mr J Rogers. Dept of Gastroenterology and Nutrition. Central Middlesex Hospital. Acton L ane. L.ondon NW 10 7NS.

Received for publication 25 February 1988.

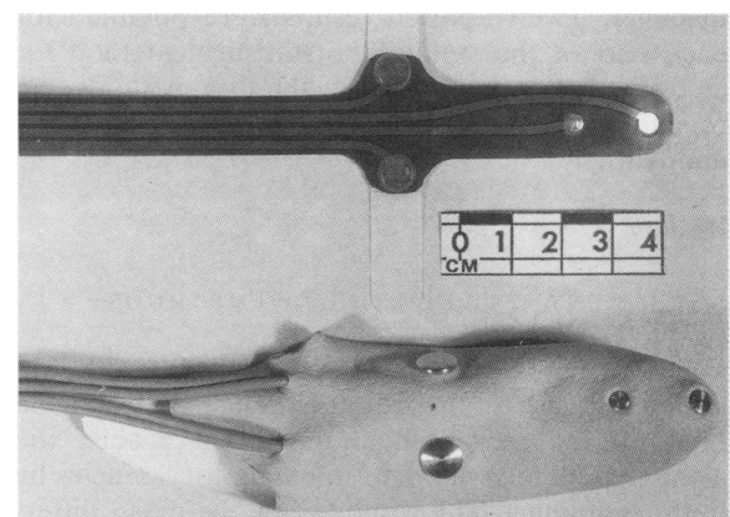

Fig. 1 New disposable (top) and standard reuseable: pudendal nerve stimulator.

hand operation. The connections are automatically engaged when the clip is closed. The stimulator has a self adhesive backing and will securely fix to most types of latex gloves, conforming easily to the contours of the index finger. The author has found that the best method is to fix the stimulator to a standard disposable glove worn over a latex examination glove for ease of operation, disposal and comfort for the patient. The stimulator is inserted and used in the same way as the reuseable type. ${ }^{134}$

\section{Methods}

A SSESSMENT

The new stimulator has been evaluated during 
Table 1 Resuseable $\mathrm{v}$ disposable stimulator

\begin{tabular}{lcc}
\hline & Reuseable & Disposable \\
\hline Mean PNTML ms (SD) & $1 \cdot 98(0 \cdot 25)$ & $1 \cdot 96(0 \cdot 25)$ \\
Mean difference (SD) & $0 \cdot 02(0 \cdot 1)$ & \\
95\% CI bias & from -0.05 to $0 \cdot 08$ & \\
$95 \%$ CI upper limit* & from $0 \cdot 18$ to 0.25 & \\
$95 \%$ CI lower limit* & from -0.21 to $-0 \cdot 15$ & \\
\hline
\end{tabular}

${ }^{*}$ Limits of agreement set at $2 \mathrm{SD}$. PNTML $=$ pudenal nerve terminal motor latencies.

routine anorectal physiology studies in 12 subjects. Six had paired measurements of their right and left pudendal nerve terminal motor latencies using both instruments in a randomised order. In the other six the measurements were repeated for both simulators to assess the repeatability of each method. In all studies the stimulus strength and duration were constant. A supramaximal $50 \mathrm{v}$ stimulus of $0 \cdot 1 \mathrm{~ms}$ duration at a rate of 1 pps was used to stimulate the pudendal nerve at the level of the ischial spines. Serial recordings made on a Medelec MS6 EMG machine. Twelve paired results were obtained for each part of the study. The statistical method for assessing agreement between the two methods and repeatability for each method was taken from Bland and Altman. ${ }^{5}$

\section{Results}

\section{AGREEMENT BETWEEN THE TWO METHODS}

(Table 1)

Figure 2 shows the results of the difference in pudendal nerve terminal motor latencies between the old and the new stimulator plotted against the average pudendal nerve terminal motor latencies by both techniques. The results show the mean differ-

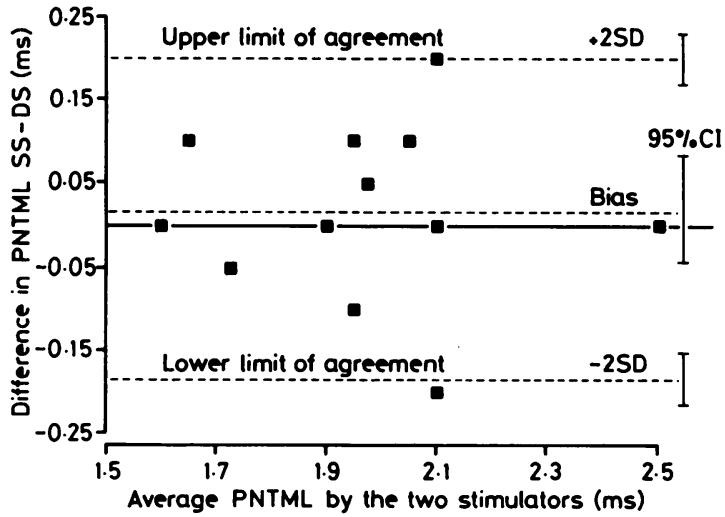

Fig. 2 Results of test of agreement: reuseable $\mathrm{v}$ disposable stimulator. ence (bias), the upper and lower limits of agreement ((2SD) from the mean difference) and their corresponding $95 \%$ confidence intervals. The results show a small bias between the two techniques but the $95 \%$ confidence intervals encompass zero and there is no statistical difference between the results obtained by the two techniques. The limits of agreement are estimated at (2SD) as this is where we would expect $95 \%$ of the differences to lie assuming a normal gaussian distribution of the data. The results are interesting in that the range of these limits is in the order of $0.4 \mathrm{~ms}$ which is large considering the range of latencies quoted in the literature for different patient groups. ${ }^{146} \mathrm{We}$ must be aware, however, that this range of limits is for agreement between the two methods under comparison. The accuracy of the techniques themselves are assessed by their repeatability.

REPEATABILITY OF EACH TECHNIQUE (Table 2) Figure $3 a$ which shows the results of repeatability for the reuseable stimulator and Figure $3 \mathrm{~b}$ which shows

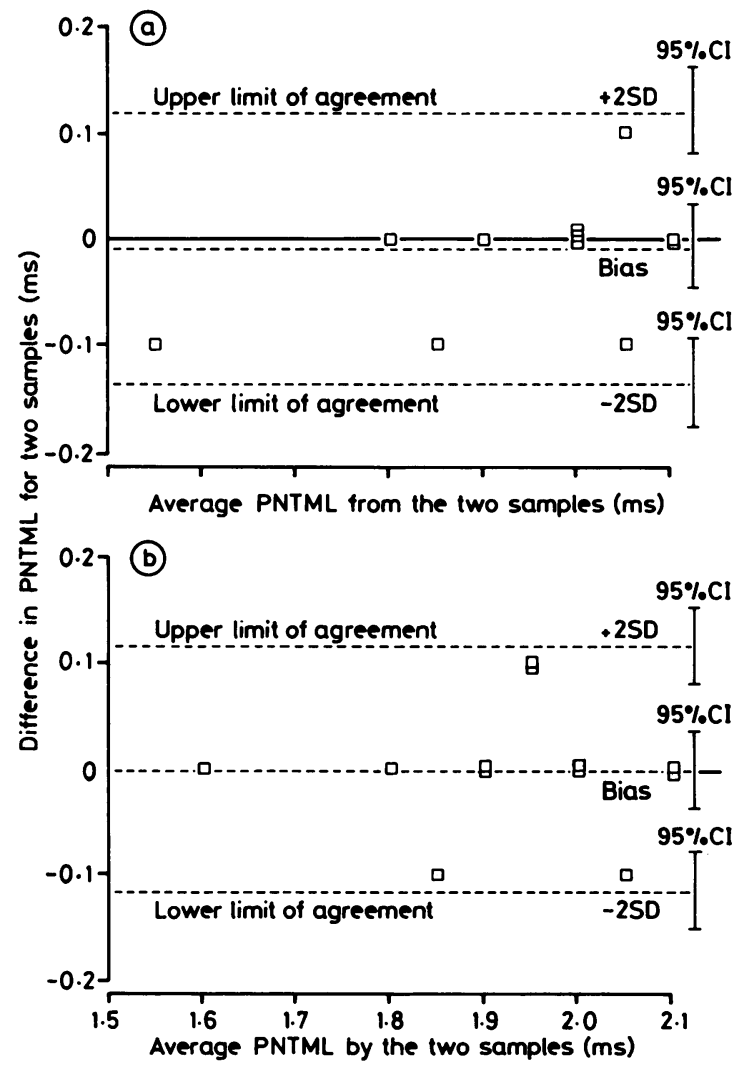

Fig. 3 Results of repeatability of stimulators. a Reuseable stimulator, b Disposable stimulator. 

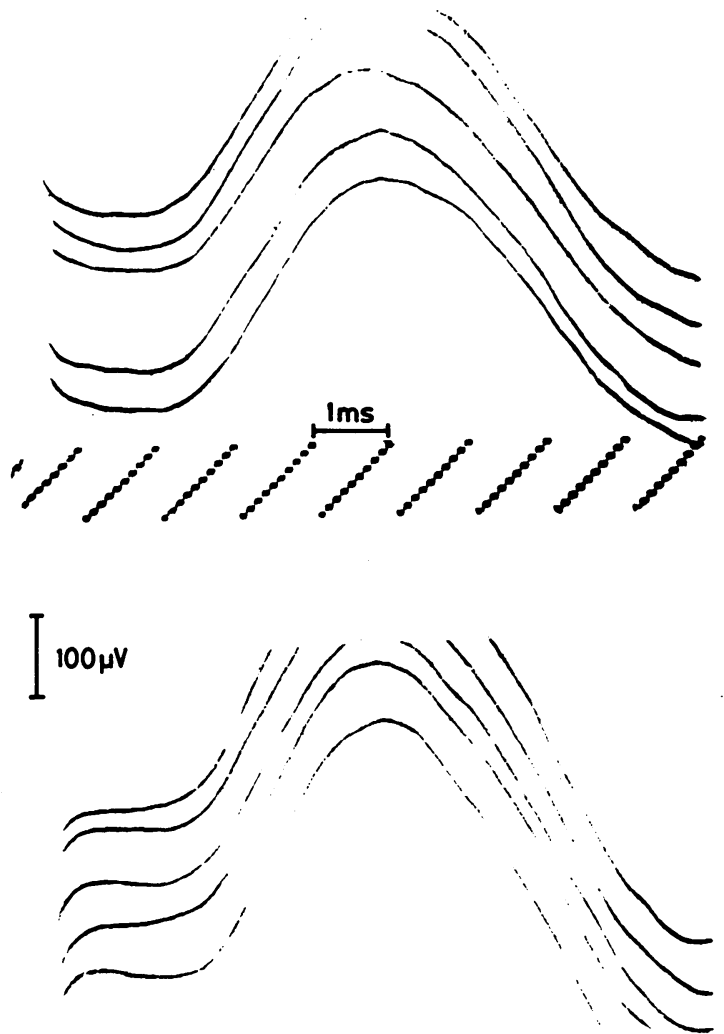

Fig. 4 Two tracings of the compound motor action potential of the external anal sphincter taken from the same subject after stimulation of the left pudendal nerve by reuseable (top) and disposable stimulator.

the results of repeatability for the disposable stimulator. The limits of agreement are similar for the two techniques and the range is at the most $0.34 \mathrm{~ms}$ but while there is no bias in the mean difference by repeated measurement with the new stimulator there is a minute negative bias in the mean difference recorded by the standard stimulator. The repeatability coefficient ${ }^{s}$ for the new stimulator is $0.11 \mathrm{~ms}$ and for the standard is $0 \cdot 12 \mathrm{~ms}$.

\section{Discussion}

A disposable pudendal nerve stimulator has the advantages of ease of operation, smaller instrument diameter, and no risk of transmission of infection between subjects. The drawback is that the flat electrode surfaces are more difficult to apply and 'skating' of the stimulus artefact across the surface of the device sometimes occurs producing an easily recognisable false potential. This is remedied by removing the stimulator and wiping any excess lubricating gel or mucus from the recording surfaces.
Table 2 Repeatability of reuseable and disposable stimulator

\begin{tabular}{|c|c|c|}
\hline Reuseable: & First sample & Second sample \\
\hline $\begin{array}{l}\text { Mean PNTML ms (SD) } \\
\text { Mean difference (SD) } \\
95 \% \text { CI bias } \\
95 \% \text { CI upper limit* } \\
95 \% \text { CI lower limit* }\end{array}$ & $\begin{array}{c}1.95(0 \cdot 17) \\
0.008(0.06) \\
\text { from }-0.05 \text { to } 0.03 \\
\text { from } 0.08 \text { to } 0.16 \\
\text { from }-0.17 \text { to }-0.09\end{array}$ & $1.95(0 \cdot 14)$ \\
\hline Disposable: & First sample & Second sample \\
\hline $\begin{array}{l}\text { Mean PNTML ms (SD) } \\
\text { Mean difference } \\
95 \% \text { CI bias } \\
95 \% \text { CI upper limit* } \\
95 \% \text { CI lower limit* }\end{array}$ & $\begin{array}{cc} & 1.93(0 \cdot 14) \\
& 1 \cdot 8 \mathrm{e}^{-17} \\
-0.3 \text { to } 0 \cdot 03 \\
\text { from } & 0 \cdot 07 \text { to } 0 \cdot 15 \\
\text { from }-0.15 \text { to }-0.07\end{array}$ & $1.93(0 \cdot 14)$ \\
\hline
\end{tabular}

${ }^{*}$ Limits of agreement set at $2 \mathrm{SD}$.

Stimulus artifact occurs less often using the reuseable stimulator as the electrode surfaces are more easily applied and are better isolated. The bias between the two techniques is small and the limits of agreement are probably wide enough to allow the control data recorded by one instrument to be applied to the other. The only reservation to this statement is that this original assessment has been made on a relatively small subject group, but the precision of the estimate as shown by the $95 \% \mathrm{CI}$ is good.

\section{AVAILABILITY}

Both types of stimulator are available and may be obtained from The Department of Gastroenterology and Nutrition, Central Middlesex Hospital, Acton Lane, London NW10 7NS.

The authors wish to thank Mr Alan Pitts for his technical assistance.

\section{References}

1 Kiff ES, Swash M. Slowed conduction in the pudendal nerves in idiopathic (neurogenic) faecal incontinence. $\mathrm{Br}$ J Surg 1987; 71: 614-6.

2 Brindley GS. Electroejaculation: its technique, neurological implications and uses. J Neurol Neurosurg Psychiatry 1981; 44: 9-18.

3 Henry MM, Snooks SJ, Barnes PRH, Swash M. Investigation of disorders of the anorectum and colon. Ann $R$ Coll Surg Engl 1985; 67: 354-60.

4 Rogers J, Henry MM, Misiewicz JJ. Combined sensory and motor deficit in primary neuropathic faecal incontinence. Gut 1988; 29: 5-9.

5 Bland JM, Altman DG. Statistical methods for assessing agreement between two methods of clinical measurement. Lancet 1986; i: 307-10.

6 Kiff ES, Swash M. Normal proximal and delayed distal conduction in the pudendal nerves of patients with idiopathic (neurogenic) faecal incontinence. J Neurol Neurosurg Psychiatry 1984; 47: 820-3. 